\title{
Measuring Trust: A Reinvestigation
}

\author{
Billur Aksoy $^{\mathrm{a}, *}$, Haley Harwell ${ }^{\mathrm{a}, \mathrm{b}}$, Ada Kovaliukaite ${ }^{\mathrm{a}}$ \\ and \\ Catherine Eckel ${ }^{\mathrm{a}}$
}

\footnotetext{
${ }^{a}$ Department of Economics, Texas A\&M University, 4228 TAMU, College Station, TX, 77843 USA

E-mail addresses: billuraksoy@tamu.edu (B. Aksoy), hharwell@ richmond.edu (H. Harwell), kovaliuk@tamu.edu (A. Kovaliukaite), ceckel@tamu.edu (C. Eckel).

${ }^{\mathrm{b}}$ Present Address: Jepson School of Leadership Studies, University of Richmond, 28 Westhampton Way, Jepson Hall, University of Richmond, VA, 23173, USA

* Corresponding Author: Billur Aksoy, Department of Economics, Texas A\&M University, 4228 TAMU College Station, TX, 77843 USA.
}

\section{Version: January 19, 2017}

\begin{abstract}
We reinvestigate the question first posed by Glaeser, Laibson, Scheinkman and Soutter (2000, GLSS hereafter): What is the best measure of trust for predicting trusting behavior? This important study, cited over 2,100 times, established that the behavior in the investment game, an incentivized measure of trust, is not correlated with the responses to the most widely used survey questions about trust, employed in the General Social Survey (GSS) and the World Values Survey (WVS). We use the GLSS protocol with one major change: we employ the original Berg et al. (1995) investment game instead of the modified version used in GLSS. The standard game endows both players, while the latter endows only the first mover, potentially changing the incentives that influence subjects' behavior. In particular, the utility from trusting behavior for inequality averse individuals may be higher, if the second movers are not endowed. Thus, such players may appear to be more trusting even though they are simply inequality averse. This causes a distortion in the laboratory measure of trust and reduces its correlation with the survey measure of trust. In support of this concern, GLSS demonstrates that the survey measure of trust is not correlated with trusting behavior in their investment game, where the second mover is not endowed. After endowing the second mover, we find the opposite. Our finding suggests that trust is a single construct, whether measured by the survey questions or by an incentivized game. This can be masked if the incentivized measure of trust is confounded with other motives.
\end{abstract}

JEL Classification: C91, D64

Keywords: Investment game, replication, lab experiment, trust, trustworthiness, inequality aversion 


\section{Introduction}

Glaeser et al. (2000) (henceforth GLSS) investigate two ways of measuring trust. The first is an incentivized measure - the percentage of endowment sent in a variant of Berg et al. (1995) "investment game." The second is a survey-based measure, which consists of the widely used General Social Survey (GSS) trust question, ${ }^{1}$ or an index of that plus two additional GSS questions. $^{2}$ An important finding in GLSS is a lack of correlation between the trusting behavior in the game and survey measures of trust, though the authors did find a positive relationship between the survey questions and trustworthiness. The authors conclude that even though trusting behavior seems to have a stable individual-specific component, ${ }^{3}$ it is at best weakly measured by typical attitudinal questions about trust. In this paper, we re-visit the investigation presented in GLSS by following their protocol, but substituting the original investment game (Berg et al., 1995). In contrast to their findings, we observe a positive and significant correlation between trusting behavior in the lab and the responses to the GSS trust question.

The game that GLSS used differs from the original investment game in two ways: the GLSS game endows only the first mover instead of both players, and uses a multiplier of two instead of three. The literature suggests that the asymmetry in endowments might be consequential for behavior of the subjects. Indeed, we find that the percentage of endowment sent is significantly lower, and the percentage returned is significantly higher, in our data as compared to GLSS. A relatively minor consideration is that the multiplier of three in an investment game is needed to distinguish between different interpretations of trustworthy behavior: paying back the entrusted amount, and splitting the total transfer received. ${ }^{4}$

The asymmetry in endowments may change the first-mover's incentives for sending money and the second-mover's propensity to return what is entrusted to him (Ciriolo, 2007; Yan and Miao, 2007; Xiao and Bicchieri, 2010; Johnson and Mislin, 2011). In particular, the utility from trusting behavior for inequality averse individuals may be higher if the second movers are not

\footnotetext{
1 “Generally speaking, would you say that most people can be trusted or that you can't be too careful in dealing with people?"

${ }^{2}$ The index combines the GSS trust question with two additional questions: "Do you think most people would try to take advantage of you if they got the chance, or would they try to be fair?" and "Would you say that most of the time people try to be helpful, or that they are mostly just looking out for themselves?"

${ }^{3}$ The authors show that the experimental measure of trust is correlated with self-reported trusting behavior and survey questions about trust towards strangers.

${ }^{4}$ This is true whenever the first mover sends all of her endowment and the second mover returns half of the doubled amount. This can be seen in Figure 1. See Ciriolo (2007) for a more in-depth analysis on this.
} 
endowed. In their meta-analysis, Johnson and Mislin (2011) studied the impact of various parameters of the investment game on trusting and trustworthy behavior. They reported that, when both players are endowed, the amount sent by the first mover is lower. Consequentially, they argued that inequality aversion might create feelings of stress and guilt, when players are asymmetrically endowed. Thus, sending more to the second mover can help eliminate these feelings. Indeed, Johansson-Stenman et al. (2013) argued specifically that altruism or inequality aversion might, in fact, explain the weak relationship between survey-based trust and trusting behavior when the second mover is not endowed. Similarly, the second mover's apparent trustworthiness may also be impacted by the fairness motives as he claims his fair share of the total payment. ${ }^{5}$ All in all, the asymmetric endowments in the GLSS game may incentivize sending more than otherwise would be observed in the standard game, which is consistent with our findings.

The weak relationship between the survey and game measures found in GLSS study has been replicated in a study in Brazil, using the same modified investment game. (Lazzarini et al. 2005). On the other hand, Johnson and Mislin (2012) found a positive cross-country correlation between the answers to the GSS trust question and average behavior in the investment game using a large data set of 80 investment game studies and country-level average survey question responses. Due to the nature of their data set, however, they were unable to analyze the relationship between the two measures of trust at an individual level. Also, they did not control for the potentially different versions of investment games used in those studies (asymmetric endowment, for example). Using the trust game with symmetric endowments, Capra et al. (2008) found that, at an individual level, after controlling for altruism, attitudinal questions are good predictors of trusting behavior. This suggests that the measures of trusting behavior may capture both trust and the impact of social preferences on behavior. An accurate behavior-based measure of trust should, thus, minimize the impact of social preferences on trusting behavior. The modified investment game used in GLSS may fail to achieve this objective as discussed below.

\section{Experimental Design}

Our experimental design and procedures follow the GLSS protocol as closely as possible, with the exception of the details of the incentivized game already mentioned (see Table 1 for details). Subjects were recruited using ORSEE (Greiner, 2004) at Texas A\&M University in April 2015.

5 Yan and Miao (2007) show how the asymmetry in endowments can change trust and reciprocity behavior in trust game. 
Subjects completed an online survey one to seven days before the experiment. The survey contained demographic and attitudinal questions about trust and trustworthiness from the GSS as well as questions designed by GLSS. A total of 98 students completed the survey and 66 of these participated in the experiment in the Economics Research Lab at Texas A\&M University. The subjects who completed the survey but did not participate in the experiment are not statistically different from those who did (see Table A.1. in Appendix A).

\begin{tabular}{|l|c|c|c|}
\hline \multicolumn{4}{|l|}{ Table 1: GLSS and Reinvestigation Design Comparison } \\
\hline & GLSS & & Reinvestigation \\
\hline Survey Payment & Not Reported* & & $\$ 5$ \\
\hline Show-up fee & Not Reported* & & $\$ 5$ \\
\hline Recruitment & Classroom & & ORSEE \\
\hline Survey & Pen and Paper & & Online \\
\hline First Mover Endowment & $\$ 15$ & & $\$ 10$ \\
\hline Second Mover Endowment & n/a & & $\$ 10$ \\
\hline Multiplier & 2 & & 3 \\
\hline Subjects & Harvard Students & & Texas A\&M Students \\
\hline Number of Subjects & 196 & & 66 \\
\hline $\begin{array}{l}\text { *We consulted with one of the authors, who was unable to recall the details about the survey payment and the } \\
\text { show-up fee. }\end{array}$ \\
\hline
\end{tabular}

Following GLSS, subjects were paired in order of arrival. They were seated in pairs and given 10 minutes to fill out a social connection survey, together with their paired partners. After completing the survey, they returned to their assigned seats to continue the experiment.

The experiment includes a baseline investment game (Berg et al. 1995) (no-promise condition) and a treatment that allows for the second mover to make a non-binding promise to return as much as is sent to her or not (promise condition). The promise is made by checking one of the two boxes on a sheet of instructions before the game starts. This sheet is displayed to the first movers before they make any transfer decisions. 34 out of 66 subjects are in the promise condition. Surveys, instructions and the script are presented in Appendix C. ${ }^{6}$

${ }^{6}$ Like GLSS, we also conducted a second experimental measure of trust: the Envelope Drop task (not reported here). Students were asked to report their valuations for an envelope containing $\$ 10$ that is addressed to the subject, and may be dropped at various public places in town. We did not find any significant correlation of the reservation 


\section{Results}

The analysis follows that presented in GLSS, which is reproduced using the original data provided by the authors. ${ }^{7}$ Table A. 2 in Appendix A compares the original and the reinvestigated subject groups in detail. In terms of the variables of interest (GSS Trust and Trust Index), two subjects pools are not statistically different from each other.

\section{Table 2: Summary Statistics}

\begin{tabular}{|l|c|c|c|c|}
\hline & \multicolumn{2}{|c|}{ GLSS } & \multicolumn{2}{c|}{ Reinvestigation } \\
\hline & Promise & No-Promise & Promise & No-Promise \\
\hline Amount Sent & $\begin{array}{c}12.45 \\
(4.33)\end{array}$ & $\begin{array}{c}12.55 \\
(4.58)\end{array}$ & $\begin{array}{c}7.06 \\
(3.45)\end{array}$ & $\begin{array}{c}7.31 \\
(2.85)\end{array}$ \\
\hline \% Sent (First Mover) & $83 \%$ & $83 \%$ & $71 \%$ & $73 \%$ \\
\hline Amount Returned & 11.58 & 12.13 & 11.53 & 13.06 \\
$(7.73)$ & $(8.29)$ & $(6.45)$ & $(8.68)$ \\
\hline Return Ratio & $43 \%$ & $47 \%$ & $55 \%$ & $55 \%$ \\
\hline $\mathbf{N}$ & 93 & 96 & 34 & 32 \\
\hline $\begin{array}{l}\text { Standard deviations are in parentheses. } \\
\text { Note: In GLSS, only the first movers are endowed with \$15 and the multiplier is 2. In this study, both movers are } \\
\text { endowed with \$10 and the multiplier is 3. }\end{array}$
\end{tabular}

Summary statistics of the experimental results for both studies are presented in Table 2. In the original study, the first movers sent a significantly higher percentage of their endowment (a measure of trust) compared to our study in both promise and no-promise conditions (Wilcoxon rank-sum test $p=0.022$ and $p=0.035$ respectively). The return ratio (a measure of trustworthiness), calculated by dividing the amount returned by the tripled amount sent (doubled amount sent in GLSS), is significantly lower in the original study in both conditions (Wilcoxon

values calculated using the Envelope Drop data in any of the regressions, and so we elected not to present the data in this paper. The materials are available on request.

7 All variables are constructed as in the original study (see Appendix Table B.1). We are able to reproduce the regression results using the data provided by the authors except for a few minor discrepancies. 
rank-sum test $p=0.002$ for promise and $p=0.017$ for no-promise).

These summary statistics suggest that using the standard investment game changes the behavior of both movers. The difference in the trusting behavior across the two studies is consistent with the findings in Johnson and Mislin (2011). They report that endowing both movers decreases the amount sent by the first mover. Additionally, the difference in the trustworthy behavior across the two studies is consistent with Ciriolo (2007), who shows that a large proportion of second movers employ a norm to equalize earnings. Thus, asymmetric endowments mean that second movers will send a lower proportion of the multiplied amount in order to equalize earnings. This finding is also supported by Figure 1 and Figure 2.

Figures 1 and 2 illustrate the relationship between the percentage of the endowment that is sent by the first mover and the percentage of the multiplied amount returned by the second mover for the original and the reinvestigation data sets, respectively. The sizes of the bubbles are proportional to the frequencies of the data points at each location. Subjects located on the solid line returned everything they received (13\% of GLSS; $3 \%$ of ours). The dashed line represents returning the exact amount sent by the first mover (57\% of GLSS; $15 \%$ of ours). Finally, the dotted line represents equal earnings. Subjects located on this line returned an amount that equalizes final earnings for both players (55\% for both GLSS and our data). ${ }^{8}$ Since the second mover in GLSS was not endowed, we cannot disentangle the motives for the 44 pairs where the first movers sent everything (\$15) and the second movers returned 50\% of the amount that was available to return $(\$ 15)$. The motive for these second movers could have been equalizing the earnings or returning the amount sent by the first mover. In our experiment, however, we observe that the dominant motive for the second movers was to equalize earnings.

Table 3 examines whether the answers to the GSS questions and other individual characteristics correlate with trust. The dependent variable is the amount sent by the first mover. The first two regressions use the original data, while the second two use our data. The six control variables (opposite gender pair dummy, promise condition dummy, gender dummy, white sender dummy, freshmen sender dummy and sender with no siblings dummy) do not correlate with the trusting behavior in the original data. In the reinvestigation data, the only significant control variable is the opposite gender pair dummy, which carries a significant positive sign.

\footnotetext{
${ }^{8}$ In GLSS, since the second mover was not endowed and multiplier was 2, the equal earnings line has a different equation $(\mathrm{y}=1.5(\mathrm{x}-5))$ than the one for our data $(\mathrm{y}=2 \mathrm{x})$ where $\mathrm{y}$ is the amount returned and $\mathrm{x}$ is the amount sent. Ciriolo (2007) offers an in-depth analysis on this.
} 
Figure 1: The Relationship between Percentage of Endowment Sent and Percent Returned of the Multiplied Amount Sent (GLSS)

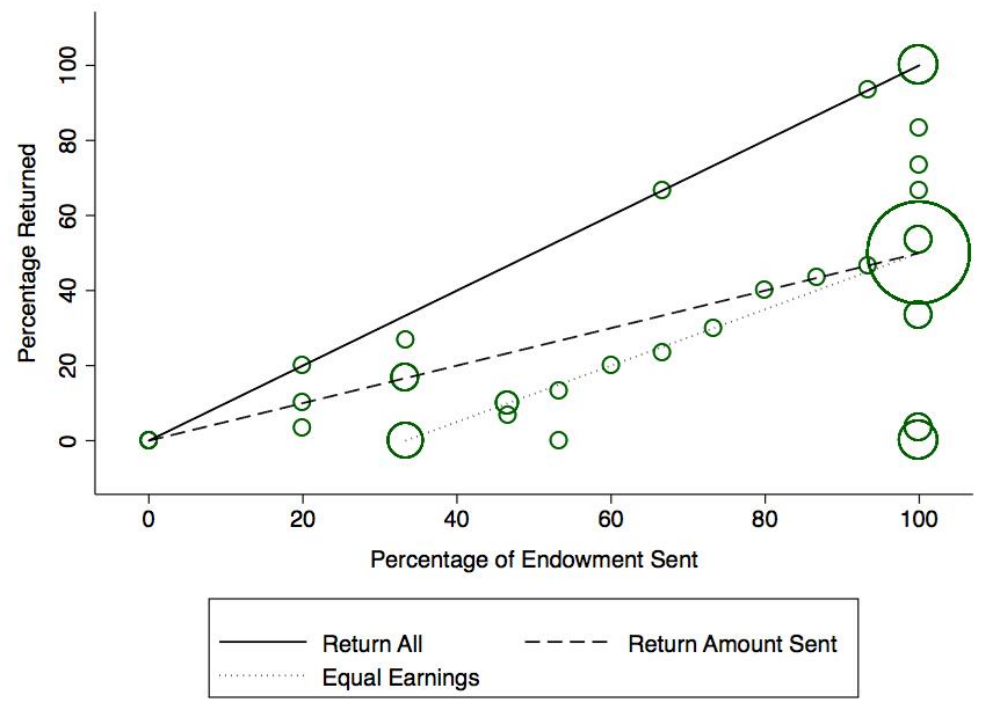

Figure 2: The Relationship between Percentage of Endowment Sent and Percent Returned of the Multiplied Amount Sent (Reinvestigation)

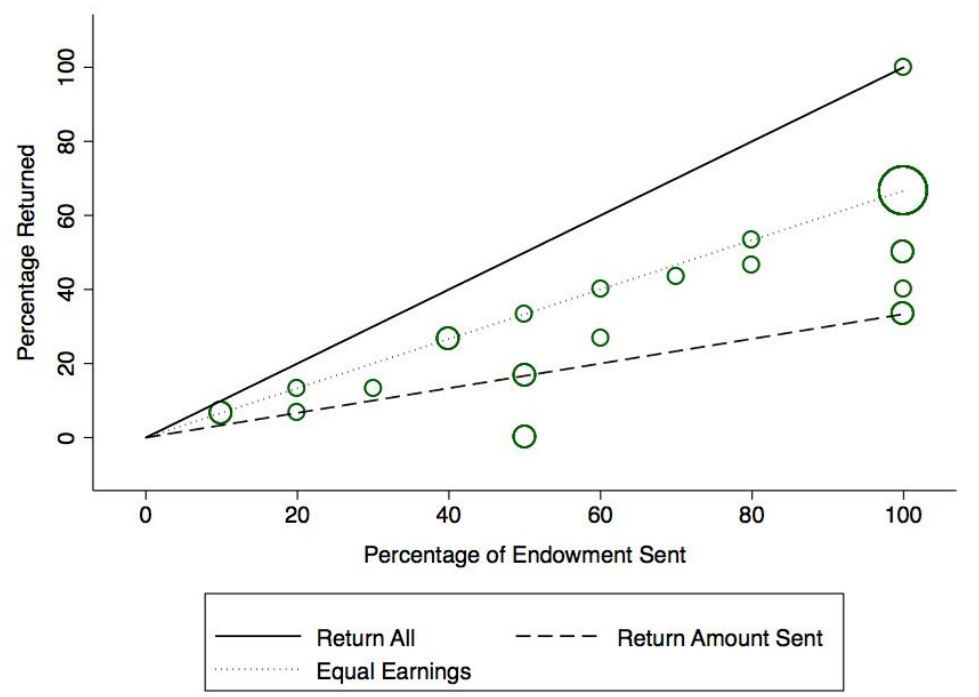


We replicate most of the original directional results. In contrast to GLSS, however, we find that both the single GSS trust question and the index of three related questions (see footnote 2) are correlated positively and significantly with trusting behavior in the game. Subjects who agree with the statement, "most people can be trusted," send on average $\$ 2.70$ more than the subjects who think that "you cannot be too careful in dealing with people."

Interestingly, GLSS showed that answers to the GSS trust questions were correlated with trustworthy rather than trusting behavior in the lab. Unlike the original study, we do not find any significant correlation between trustworthiness and the survey measures. Table A.3 in Appendix A presents these results.

\begin{tabular}{|c|c|c|c|c|}
\hline \multicolumn{5}{|c|}{ Table 3: Amount Sent as a Function of Sender Characteristics } \\
\hline & (1) & (2) & (1) & (2) \\
\hline Opposite gender & $\begin{array}{l}-0.670 \\
(1.130)\end{array}$ & $\begin{array}{l}-0.128 \\
(1.112)\end{array}$ & $\begin{array}{c}3.495 * * * \\
(1.027)\end{array}$ & $\begin{array}{c}3.171 * * * \\
(1.050)\end{array}$ \\
\hline Promise treatment & $\begin{array}{c}0.043 \\
(1.024)\end{array}$ & $\begin{array}{c}-0.097 \\
(1.015)\end{array}$ & $\begin{array}{l}-0.029 \\
(1.039)\end{array}$ & $\begin{array}{l}-0.452 \\
(1.061)\end{array}$ \\
\hline Male & $\begin{array}{c}0.147 \\
(1.197)\end{array}$ & $\begin{array}{c}0.623 \\
(1.174)\end{array}$ & $\begin{array}{c}0.514 \\
(0.969)\end{array}$ & $\begin{array}{c}0.392 \\
(1.008)\end{array}$ \\
\hline White & $\begin{array}{l}-0.330 \\
(1.030)\end{array}$ & $\begin{array}{l}-0.640 \\
(1.025)\end{array}$ & $\begin{array}{l}-0.720 \\
(1.062)\end{array}$ & $\begin{array}{l}-0.359 \\
(1.082)\end{array}$ \\
\hline Freshman & $\begin{array}{l}-0.205 \\
(1.136)\end{array}$ & $\begin{array}{l}-0.434 \\
(1.125)\end{array}$ & $\begin{array}{l}-2.041 \\
(1.559)\end{array}$ & $\begin{array}{l}-2.140 \\
(1.625)\end{array}$ \\
\hline Only child & $\begin{array}{l}-1.620 \\
(1.531)\end{array}$ & $\begin{array}{l}-1.724 \\
(1.474)\end{array}$ & $\begin{array}{c}0.282 \\
(1.031)\end{array}$ & $\begin{array}{l}-0.263 \\
(1.069)\end{array}$ \\
\hline GSS trust & $\begin{array}{c}0.220 \\
(1.022)\end{array}$ & & $\begin{array}{c}2.711 * * \\
(1.104)\end{array}$ & \\
\hline Trust index & & $\begin{array}{l}-0.094 \\
(0.222)\end{array}$ & & $\begin{array}{l}0.450 * \\
(0.240)\end{array}$ \\
\hline Constant & $\begin{array}{c}12.773 * * * \\
(2.695)\end{array}$ & $\begin{array}{c}12.386^{* * * *} \\
(2.660)\end{array}$ & $\begin{array}{c}4.461 * * * \\
(1.383)\end{array}$ & $\begin{array}{c}5.905 * * * \\
(1.288)\end{array}$ \\
\hline Adj. $\mathrm{R}^{2}$ & -0.059 & -0.050 & 0.2814 & 0.2179 \\
\hline Observations & 93 & 90 & 33 & 33 \\
\hline
\end{tabular}




\section{Conclusions}

This paper follows the GLSS protocol, replacing the modified version of the Berg et al. (1995) investment game with the original game. ${ }^{9}$ To compare to the GLSS results, we observe a significantly lower percentage of the endowment sent and a higher percentage returned. These findings are in line with the literature that shows how asymmetric endowments change the behavior in the investment game (Ciriolo, 2007; Yan and Miao, 2007; Xiao and Bicchieri, 2010; Johnson and Mislin, 2011). Despite a smaller sample, we find evidence that the answers to the GSS trust questions are significantly correlated with trusting behavior in the lab, when the standard game is used. Additionally, in contrast to GLSS, we do not find any evidence that the GSS trust questions are correlated with trustworthiness.

The behavior observed in the trust game most likely measures trust along with other-regarding preferences. However, we argue that other regarding preferences might be more pronounced in the presence of asymmetric endowments. This could explain the different findings between this paper and GLSS. We find supporting evidence for the discussion by Johansson-Stenman et al. (2013), who noted that altruism or inequality aversion might, in fact, explain the weak relationship between survey-based trust and trusting behavior when the second mover is not endowed.

The main contribution of GLSS was evidence against correlation between trusting behavior in the investment game and the survey measures of trust. This important finding has discouraged many researchers from using the survey questions regarding trust. Instead, economists replaced the survey questions with incentivized games, which are costly and especially complicated to implement in field studies (see Fehr et al. (2003) for an example). However, our findings suggest that it is safe to use survey measures of trust.

\footnotetext{
${ }^{9}$ We do not attempt to disentangle the effects of changing the endowment and the multiplier in the game. However, based on the existing research, we believe that the endowment is the most important change (see Ciriolo, 2007; Johnson and Mislin, 2011; Johansson-Stenman et al.,2013).
} 


\section{Acknowledgments}

We would like to thank David I. Laibson for sharing data and materials from the original study. We also thank Mackenzie Alston, Noah Bacine, Abigail Peralta, Zoey Zhengzheng Wang, Wei Zhan, and the participants at the Economic Science Association North American Meeting 2015 in Dallas and the Texas Experimental Association Symposium 2016 in Houston. Funding was provided by the Sara and John Lindsey Professorship, College of Liberal Arts, Texas A\&M University. 


\section{References}

Berg, Joyce, John Dickhaut, and Kevin McCabe. "Trust, reciprocity, and social history." Games and Economic Behavior 10.1 (1995): 122-142.

Capra, C. Mónica, Kelli Lanier, and Shireen Meer. "Attitudinal and behavioral measures of trust: a new comparison." Working Paper Emory University (2008).

Ciriolo, Emanuele. "Inequity aversion and trustees' reciprocity in the trust game." European Journal of Political Economy 23, no. 4 (2007): 1007-1024.

Fehr, Ernst, Urs Fischbacher, Bernhard Von Rosenbladt, Jürgen Schupp, and Gert G. Wagner. "A nation-wide laboratory: examining trust and trustworthiness by integrating behavioral experiments into representative survey." (2003).

Glaeser, Edward L., David I. Laibson, Jose A. Scheinkman, and Christine L. Soutter. "Measuring trust." Quarterly Journal of Economics 115.3 (2000): 811-846.

Greiner, Ben. "An online recruitment system for economic experiments." (2004): 79-93.

Johansson-Stenman, Olof, Minhaj Mahmud, and Peter Martinsson. "Trust, trust games and stated trust: Evidence from rural Bangladesh." Journal of Economic Behavior \& Organization 95 (2013): 286-298.

Johnson, Noel D., and Alexandra A. Mislin. "Trust games: A meta-analysis." Journal of Economic Psychology 32.5 (2011): 865-889.

Johnson, Noel D., and Alexandra Mislin. "How much should we trust the World Values Survey trust question?." Economics Letters 116.2 (2012): 210-212.

Lazzarini, Sergio. G., Regina Madalozzo, Rinaldo Artes, and Jose de Oliveira Siqueira. "Measuring trust: An experiment in Brazil." Brazilian Journal of Applied Economics 9.2 (2005): 153-169.

Xiao, Erte, and Cristina Bicchieri. "When equality trumps reciprocity." Journal of Economic Psychology 31, no. 3 (2010): 456-470.

Yan, Jin, and Lingling Miao. "Effects of endowments on reciprocal behaviors." In 2007 International Conference on Wireless Communications, Networking and Mobile Computing. 2007. 


\section{SUPPLEMENTARY MATERIALS}

APPENDIX A: Additional Tables and Analysis

\begin{tabular}{|c|c|c|c|}
\hline & Survey Only & $\begin{array}{c}\text { Both Survey and } \\
\text { Experiment }\end{array}$ & P-values \\
\hline GSS Trust & $\begin{array}{c}0.45 \\
(0.51)\end{array}$ & $\begin{array}{c}0.38 \\
(0.49)\end{array}$ & 0.659 \\
\hline GSS Fair & $\begin{array}{c}0.42 \\
(0.50)\end{array}$ & $\begin{array}{c}0.43 \\
(0.50)\end{array}$ & 1.000 \\
\hline GSS Helpful & $\begin{array}{c}0.48 \\
(0.50)\end{array}$ & $\begin{array}{c}0.39 \\
(0.51)\end{array}$ & 0.388 \\
\hline Freshman & $\begin{array}{c}0.13 \\
(0.34)\end{array}$ & $\begin{array}{c}0.14 \\
(0.35)\end{array}$ & 1.000 \\
\hline Male & $\begin{array}{c}0.48 \\
(0.51)\end{array}$ & $\begin{array}{c}0.48 \\
(0.47)\end{array}$ & 1.000 \\
\hline White & $\begin{array}{c}0.39 \\
(0.50)\end{array}$ & $\begin{array}{c}0.47 \\
(0.50)\end{array}$ & 0.519 \\
\hline Only child & $\begin{array}{c}0.42 \\
(0.50)\end{array}$ & $\begin{array}{c}0.39 \\
(0.49)\end{array}$ & 0.826 \\
\hline \multicolumn{4}{|c|}{$\begin{array}{l}\text { Standard deviations are in parentheses. The p-values reported are computed by using Fisher's Exact Test. } \\
\text { Note that one subject participated in the experiment without completing the survey. Our analysis does not } \\
\text { include this subject and his partner. }\end{array}$} \\
\hline
\end{tabular}

\begin{tabular}{|c|c|c|c|}
\hline \multicolumn{4}{|c|}{ Table A.2: Original and Reinvestigation Subject Comparison } \\
\hline & GLSS & Reinvestigation & P-values \\
\hline Male & $\begin{array}{c}0.33 \\
(0.47)\end{array}$ & $\begin{array}{c}0.48 \\
(0.50)\end{array}$ & $0.053^{+}$ \\
\hline Freshman & $\begin{array}{c}0.69 \\
(0.46)\end{array}$ & $\begin{array}{c}0.14 \\
(0.35)\end{array}$ & $0.000^{+}$ \\
\hline Only Child & $\begin{array}{c}0.11 \\
(0.32) \\
\end{array}$ & $\begin{array}{c}0.39 \\
(0.49)\end{array}$ & $0.000^{+}$ \\
\hline White & $\begin{array}{c}0.61 \\
(0.49)\end{array}$ & $\begin{array}{c}0.47 \\
(0.50)\end{array}$ & $0.060^{+}$ \\
\hline GSS Trust & $\begin{array}{c}0.47 \\
(0.50)\end{array}$ & $\begin{array}{c}0.38 \\
(0.49)\end{array}$ & $0.249^{+}$ \\
\hline Trust Index & $\begin{array}{c}0.01 \\
(2.21)\end{array}$ & $\begin{array}{c}0.01 \\
(2.18)\end{array}$ & $0.067^{++}$ \\
\hline \multicolumn{4}{|c|}{$\begin{array}{l}\text { Standard deviations are in parentheses. } \\
+{ }^{+} \text {Fisher Exact Test } \\
{ }^{++} \text {Kolmogorov Smirnov test }\end{array}$} \\
\hline
\end{tabular}




\begin{tabular}{|c|c|c|c|c|c|c|c|c|}
\hline & \multicolumn{4}{|c|}{ GLSS } & \multicolumn{4}{|c|}{ Reinvestigation } \\
\hline & $(1)$ & $(2)$ & (3) & $(4)$ & $(1)$ & $(2)$ & (3) & $(4)$ \\
\hline Different sexes & $\begin{array}{c}0.003 \\
(0.053) \\
\end{array}$ & $\begin{array}{l}-0.007 \\
(0.052)\end{array}$ & $\begin{array}{c}0.006 \\
(0.055)\end{array}$ & $\begin{array}{c}0.001 \\
(0.065)\end{array}$ & $\begin{array}{l}-0.138 \\
(0.083)\end{array}$ & $\begin{array}{c}-0.146 \\
(0.086)\end{array}$ & $\begin{array}{c}-0.170 * \\
(0.082)\end{array}$ & $\begin{array}{c}1.050 \\
(0.728)\end{array}$ \\
\hline Promise & $\begin{array}{c}-0.043 \\
(0.051) \\
\end{array}$ & $\begin{array}{c}-0.007 \\
(0.051) \\
\end{array}$ & $\begin{array}{c}-0.031 \\
(0.052) \\
\end{array}$ & $\begin{array}{c}0.017 \\
(0.063) \\
\end{array}$ & $\begin{array}{c}-0.018 \\
(0.072) \\
\end{array}$ & $\begin{array}{c}-0.001 \\
(0.076) \\
\end{array}$ & $\begin{array}{c}-0.028 \\
(0.072) \\
\end{array}$ & $\begin{array}{r}0.789 \\
(0.526) \\
\end{array}$ \\
\hline Male & $\begin{array}{c}0.027 \\
(0.059) \\
\end{array}$ & $\begin{array}{c}0.047 \\
(0.058) \\
\end{array}$ & $\begin{array}{c}0.013 \\
(0.061) \\
\end{array}$ & $\begin{array}{c}-0.015 \\
(0.073) \\
\end{array}$ & $\begin{array}{l}-0.059 \\
(0.076)\end{array}$ & $\begin{array}{c}-0.041 \\
(0.077) \\
\end{array}$ & $\begin{array}{c}-0.013 \\
(0.076) \\
\end{array}$ & $\begin{array}{c}-0.619 \\
(0.596) \\
\end{array}$ \\
\hline White & $\begin{array}{c}0.075 \\
(0.054) \\
\end{array}$ & $\begin{array}{c}0.072 \\
(0.052) \\
\end{array}$ & $\begin{array}{c}0.074 \\
(0.055) \\
\end{array}$ & $\begin{array}{c}0.062 \\
(0.065) \\
\end{array}$ & $\begin{array}{r}-0.063 \\
(0.08) \\
\end{array}$ & $\begin{array}{c}-0.068 \\
(0.084) \\
\end{array}$ & $\begin{array}{c}-0.064 \\
(0.079) \\
\end{array}$ & $\begin{array}{r}-0.090 \\
(0.204) \\
\end{array}$ \\
\hline Freshman & $\begin{array}{c}-0.072 \\
(0.055)\end{array}$ & $\begin{array}{c}-0.052 \\
(0.055)\end{array}$ & $\begin{array}{c}-0.083 \\
(0.056)\end{array}$ & $\begin{array}{c}-0.009 \\
(0.071)\end{array}$ & $\begin{array}{c}0.032 \\
(0.113) \\
\end{array}$ & $\begin{array}{c}0.03 \\
(0.118) \\
\end{array}$ & $\begin{array}{c}0.032 \\
(0.111) \\
\end{array}$ & $\begin{array}{c}0.94 \\
(0.786)\end{array}$ \\
\hline Only child & $\begin{array}{c}-0.217 * * \\
(0.092) \\
\end{array}$ & $\begin{array}{c}-0.242 * * * \\
(0.089)\end{array}$ & $\begin{array}{c}-0.218 * * \\
(0.088) \\
\end{array}$ & $\begin{array}{c}-0.191 * \\
(0.112)\end{array}$ & $\begin{array}{c}-0.12 \\
(0.077)\end{array}$ & $\begin{array}{c}-0.109 \\
(0.079) \\
\end{array}$ & $\begin{array}{c}-0.06 \\
(0.081) \\
\end{array}$ & $\begin{array}{c}-0.018 \\
(0.240) \\
\end{array}$ \\
\hline GSS trust & $\begin{array}{c}0.106^{* *} \\
(0.051)\end{array}$ & & & & $\begin{array}{c}-0.1 \\
(0.076)\end{array}$ & & & \\
\hline Trust index & & $\begin{array}{c}0.043 * * * \\
(0.012) \\
\end{array}$ & & & & $\begin{array}{c}-0.003 \\
(0.018) \\
\end{array}$ & & \\
\hline Self-reported trustworthiness & & & $\begin{array}{c}-0.026 \\
(0.026) \\
\end{array}$ & & & & $\begin{array}{c}0.095 \\
(0.059) \\
\end{array}$ & \\
\hline Honesty index & & & & $\begin{array}{c}0.01 \\
(0.008) \\
\end{array}$ & & & & $\begin{array}{c}0.127 \\
(0.495) \\
\end{array}$ \\
\hline Constant & $\begin{array}{c}0.174 \\
(0.153) \\
\end{array}$ & $\begin{array}{c}0.165 \\
(0.151) \\
\end{array}$ & $\begin{array}{l}0.373 * \\
(0.213)\end{array}$ & $\begin{array}{c}0.261 \\
(0.186) \\
\end{array}$ & $\begin{array}{c}0.676^{* * * *} \\
(0.146)\end{array}$ & $\begin{array}{c}0.595 * * * \\
(0.14) \\
\end{array}$ & $\begin{array}{c}0.03 \\
(0.372) \\
\end{array}$ & $\begin{array}{c}0.198 \\
(0.495) \\
\end{array}$ \\
\hline Adj.R ${ }^{2}$ & 0.161 & 0.232 & 0.138 & 0.0359 & 0.0604 & -0.0072 & 0.00898 & 0.521 \\
\hline Observations & 90 & 88 & 91 & 64 & 33 & 33 & 33 & 10 \\
\hline
\end{tabular}




\section{Appendix B}

\begin{tabular}{|c|c|c|}
\hline Variable Name & Question/description & $\begin{array}{c}\text { Answer range } \\
\text { (Reinvestigation) }\end{array}$ \\
\hline Amount sent & Amount sent by the first mover in trust game & $0-10$ \\
\hline Different Sex & First and second movers have different sex & $\begin{array}{l}\text { Yes-1 } \\
\text { No-0 }\end{array}$ \\
\hline Male & Subject is male & $\begin{array}{l}\text { Yes-1 } \\
\text { No-0 }\end{array}$ \\
\hline White & Subject is white & $\begin{array}{l}\text { Yes-1 } \\
\text { No-0 }\end{array}$ \\
\hline Freshman & Subject is freshman & $\begin{array}{l}\text { Yes-1 } \\
\text { No-0 }\end{array}$ \\
\hline Only Child & Subject is the only child in the family & $\begin{array}{l}\text { Yes-1 } \\
\text { No-0 }\end{array}$ \\
\hline GSS Trust & $\begin{array}{l}\text { "Generally speaking, would you say that most people can be trusted } \\
\text { or that you can't be too careful in dealing with people?" }\end{array}$ & $\begin{array}{l}\text { Most people can be } \\
\text { trusted-1 } \\
\text { Can't be too } \\
\text { careful- } 0\end{array}$ \\
\hline Trust Index & $\begin{array}{l}\text { Normalized index of responses to } 3 \text { trust questions: } \\
\text { 1. GSS Trust Question } \\
\text { 2. Do you think that most people would try to take advantage } \\
\text { of you if they got the chance, or would they try to be fair? } \\
\text { 3. Would you say that most of the time people try to be } \\
\text { helpful, or that they are mostly just looking for themselves? }\end{array}$ & $(-3.6,2.5)$ \\
\hline Return Ratio & Amount Returned/ (Amount Sent*3) & $(0,1)$ \\
\hline $\begin{array}{l}\text { Self-Reported } \\
\text { Trustworthiness }\end{array}$ & "I am always trustworthy" & $\begin{array}{l}\text { Disagree Strongly-1 } \\
\text { Agree Strongly-6 }\end{array}$ \\
\hline Honesty Index & $\begin{array}{l}\text { Normalized index of response to four questions rating frequency of } \\
\text { lying to parents, close friends, roommates, acquaintances partners. }\end{array}$ & $(-10.8,6.2)$ \\
\hline
\end{tabular}




\section{APPENDIX C: Instructions and Surveys}

\section{C.1 Shortened Version of the Online Survey (Full Survey is available upon request).}

This survey is designed to provide us with information about the study participants to help us gain additional insights into the results we will observe in the experiment. Your responses to this survey are guaranteed to be kept strictly anonymous. The survey should take approximately 20 minutes of your time. You will be paid $\$ 5$ for completing the survey and $\$ 5$ as a show up fee upon your arrival to the experiment. At the end of the experiment you will receive any earnings you will accumulate in the experiment. In order to get paid and participate in the experiment you must arrive to the Economics Research Laboratory on time. Please attempt to answer all the questions that follow to the best of your ability. Some questions are about facts (e.g. date of birth), and some of the questions are about your opinions. You are required to answer all the questions in order to participate in the experiment and receive your payment. This survey will take approximately 20 minutes. If for some reason you need to leave the survey, you can return using the link provided in the email. Any answers you have input into the survey will be saved. We appreciate your time. Thank you for your participation, The ERL Team

Q1. What is your sex?

Female (1)

O Male (2)

Q2. What race do you consider yourself?

Q3. How many older brothers and sisters do you have? Include stepbrothers, stepsisters, and children adopted by your parents. (if your answer is zero, be sure to indicate zero)

Older Brother(s) (1)

Older Sister(s) (2)

Q4. How many younger brothers and sisters do you have? Include stepbrothers, stepsisters, and children adopted by your parents. (if your answer is zero, be sure to indicate zero) Younger Brother(s) (1) Younger Sister(s) (2)

Q5. What year are you in here at TAMU?

Freshman (1)

Sophomore (2)

O Junior (3)

O Senior (4)

O Graduate Student (5) 
Q6. How often do you lie to your parents?

O Very often (1)

O Often (2)

O Sometimes (3)

O Rarely (4)

O Never (5)

Prefer Not to Answer (6)

Q7. How often do you lie to your roommates?

$\mathrm{O}$ Very often (1)

O Often (2)

Sometimes (3)

O Rarely (4)

O Never (5)

O Prefer Not to Answer (6)

Q8. How often do you lie to casual acquaintances?

O Very often (1)

O Often (2)

O Sometimes (3)

O Rarely (4)

O Never (5)

O Prefer Not to Answer (6)

Q9. How often do you lie to close friends?

O Very often (1)

Often (2)

O Sometimes (3)

O Rarely (4)

O Never (5)

Prefer Not to Answer (6)

Q10. Do you have a steady boyfriend/girlfriend?

If yes is selected:

If you have a girlfriend/boyfriend, how often do you lie to her/him?

O Very often (1)

O Often (2)

O Sometimes (3)

O Rarely (4)

O Never (5)

O Prefer Not to Answer (6)

Q11. I am always trustworthy. (Indicate your level of agreement or disagreement with this statement.)

O Disagree Strongly (1)

O Disagree Somewhat (2) 
Disagree Slightly (3)

O Agree Slightly (4)

O Agree Somewhat (5)

O Agree Strongly (6)

Q12. Would you say that most of the time people...

O try to be helpful. (1)

$\bigcirc$ are mostly just looking out for themselves. (2)

Q13. Do you think most people would try to...

$O$ take advantage of you if they got a chance. (1)

be fair. (2)

Q14. Generally speaking, would you say...

O that most people can be trusted. (1)

you can't be too careful in dealing with people. (2)

\section{C.2 Script for the Experiment}

Welcome, Please sit down anywhere in the lab with the person that you are paired with. You may ignore the stickers on the computer monitor for now.

Hi, thanks for coming to today's study.

I am [Experimenter], a graduate student here at Texas A\&M University.

[Experiment Assistant] is our monitor today and will be helping with the experiment. We also have a monitor who will be helping behind the scenes of the experiment to make sure everything is completely confidential and she will be paying you in private at the end of the experiment.

We will be doing some activities and a survey because we are interested in how people make everyday decisions about money, and so in our studies people make some REAL decisions with REAL money.

I will be reading from a script today. We need to do that to make sure that we always say the same thing. From now until the end of the study, please do not talk to anyone except one of the experimenters unless instructed to do so. If you have any questions about the instructions please raise your hand.

You will receive $\$ 5$ for coming here today. You will also receive $\$ 5$ for completing the online survey. This $\$ 10$ is yours to keep. There will be opportunities for you to earn additional money today: we will explain how as we go along.

Please listen carefully to all instructions that I give you. This is very important. The choice that you make will determine how much additional money you will be paid today.

When you came in today, you were given an ID card. You will later find a white card with identical ID number at the seat assigned to you. There are two unique colors of ID cards. Please 
take note which color you were assigned. We use ID numbers to keep track of the decisions that everyone makes, and you will need the number to claim your earnings at the end.

\section{Social Connection Instructions:}

Thank you for volunteering to participate in this economics experiment. The instructions you are reading are self-explanatory.

[Experiment Assistant] is going to pass out an envelope with two sets of instructions and the questionnaire inside now to each pair. Please make sure the Group ID number on the paper matches both of your personal ID numbers (the actual 2 digit number) on your colored card. Each of you can look at a copy of the instructions and follow along.

We will read these instructions aloud so please follow along. You and the person you are paired with in this experiment will always be reading the exact same documents; there is no deception involved. The instructions have been designed with an emphasis on clarity (which at times leads them to be a little repetitive). The experiment has been designed to use standardized procedures (which at times leads the experiment to feel a little formal). We will not answer any questions during this part of the experiment. If you have any questions, you should read back through the instructions. Now that the experiment has begun, please do not talk unless you are instructed to do so. However, if at any time you wish to end your participation in the experiment, please notify the experimenters immediately.

You have received either orange or green cards with your personal ID Number. Please remember whether you are ORANGE or GREEN in all future portions of this experiment.

ORANGEs and GREENs participate in most of the experiment in ORANGE-GREEN pairs. In this first portion of the experiment, which will take about ten minutes, each ORANGE-GREEN pair will get to know each other. This is the only exception to the experiment's NO-TALKING rule.

You will now spend ten minutes talking with each other and jointly filling out the enclosed ORANGE-GREEN QUESTIONNAIRE and the accompanying LIST PAGE. When you are finished, please be sure the total numbers of names on the List Page has been written down under Question 8 on the Questionnaire, and then have the ORANGE person pocket the List Page, so that researchers never see the names; this protects your anonymity. Put the completed ORANGEGREEN QUESTIONNAIRE, into the WHITE ENVELOPE that it came to you in, and drop the envelope in the box indicated by the monitor. (Box is located at the front of the room) These instructions can then be trashed.

One way that might be easy to see who you know in common would be to look at your social media page (if you have one) and see if you have any friends in common. You may use your phone for this part of the experiment to see if there are mutual friends. Also using the survey will help you think about who you might know in common. 
Begin talking for ten minutes when the monitor instructs you to do so. Please do not stop until the monitor instructs you to stop. Even if you do not think you know anyone in common, please keep trying to uncover some connections between the two of you, however remote they may be. It is important to use the entire 10 minutes.

Your ten minutes are over. Please place the survey back in the white envelope and bring it to the front of the room and place in the box. The orange member should hold on to the list page.

Now please find the computer with a sticker on the monitor that matches your id number and color. The green stickers are on my right side of the room and the orange stickers are on my left side of the room.

Also, please now turn off your cell phones and we will begin the next part of the experiment.

\section{Transfer Game Instructions: (If Baseline)}

Now you will receive a new decision form. The game we are about to play is a transfer game.

[Experiment Assistant] will now hand out an envelope with your group ID on the front and a decision sheet inside to the orange members of the pairs.

In this decision form: Please write only what you have been asked to write. Extraneous marks, anywhere on this form, invalidate the Transfer Game; in that case neither one of you will be paid for your participation in this portion of the experiment.

There are two sections of this form. The top part will be filled out by the Orange player and the next portion will be filled out by the green player.

You and this other person will make decisions that affect both of your earnings. You both start with $\$ 10$.

The orange player goes first, and can send none, some, or all of their $\$ 10$ to the green player. Any money the orange player sends to the green player will be tripled.

The green player will have the $\$ 10$ they started out with plus three times the amount of money sent to them by the orange player. The green player may send none, some, or all of the tripled money back to the orange player. Any money sent to the orange player will not be multiplied. Both decisions together determine the payoffs of both players.

Now Orange players make your decision to send some, none or all of your ten dollars to the green player. Orange players please make your decision now.

After making your transfer decision please place it back in the envelope and raise your hand. [Experiment Assistant] will come by and pick up your envelope, the outside experimenter will check for erroneous marks and then [Experiment Assistant] will redistribute the envelopes to the green members.

(Wait for envelopes to be picked up and redelivered to green) 
[Experiment Assistant] has now returned the envelopes to the green players. Please open the envelope and you will see how much money was transferred to you by the orange player. Now please decide how much you would like to send back to the orange player. Remember this amount can be whole dollar increments. You can send some, none, or the entire tripled amount received.

Green players please make your decision now.

Raise your hand after you complete this decision and [Experiment Assistant] will pick the envelope with the decision form up. We will take the envelopes to the outside experimenter who will allocate the money for payment.

We will then begin a new task. This will be the bonus-winning task.

\section{Transfer Game Instructions: (If Promise)}

Now you will receive a new decision form. The game we are about to play is a transfer game.

[Experiment Assistant] will now hand out an envelope with your group ID on the front and a decision sheet inside to the green members of the pairs.

In this decision form: Please write only what you have been asked to write. Extraneous marks, anywhere on this form, invalidate the Transfer Game; in that case neither one of you will be paid for your participation in this portion of the experiment.

There are three sections of this form. The first and third part will be filled out by the green player and the second portion will be filled out by the orange player.

You and this other person will make decisions that affect both of your earnings. You both start with $\$ 10$.

The green player has an opportunity to make a non-binding promise to the orange player. They will do this by checking one of two statements discussed shortly.

After the green player makes the non-binding promise decision.

The orange player goes next, and can send none, some, or all of their $\$ 10$ to the green player. Any money the orange player sends to the green player will be tripled.

The green player will now have the $\$ 10$ they started out with plus three times the amount of money sent to them by the orange player. The green player may send none, some, or all of the tripled money back to the orange player. Any money sent to the orange player will not be multiplied. Both decisions together determine the payoffs of both players.

The promise that the green player can make is to repay the orange player at least as much as they sent. The other option is to make no promise. When the orange player receives the envelope the green player will either have made this non-binding promise by selecting the box indicating this. 
Otherwise, they will select the box indicating no promise. This promise will not affect the payments of either the orange or the green members.

After then green player completes this non-binding promise decision, please raise your hand, [Experiment Assistant] will pick up your envelopes and the outside experimenter will check for extraneous marks or invalid decisions. Then [Experiment Assistant] will bring the envelopes back and distribute them to the orange members of the pair for their transfer decision.

Green players please select if you would like to make a non-binding promise to the orange player now.

(Wait for envelopes to be picked up and redelivered to orange)

[Experiment Assistant] has now returned the envelopes to the orange players. Please open the envelope and you will see if the green player made a non-binding promise to return at least what you send to him.

Now Orange players make your decision to send some, none or all of your ten dollars to the green player. Orange players please make your decision now.

After making your transfer decision please place it back in the envelope and raise your hand. [Experiment Assistant] will come by and pick up you envelope, the outside experimenter will check for erroneous marks and then [Experiment Assistant] will redistribute the envelopes to the green members.

(Wait for envelopes to be picked up and redelivered to green)

[Experiment Assistant] has now returned the envelopes to the green players. Please open the envelope and you will see how much money was transferred to you by the orange player. Now please decide how much you would like to send back to the orange player. Remember this amount can be whole dollar increments. You can send some, none, or the entire tripled amount received.

Green players please make your decision now.

Raise your hand after you complete this decision and [Experiment Assistant] will pick the envelope with the decision form up. We will take the envelopes to the outside experimenter who will allocate the money for payment.

We will then begin a new task. This will be the bonus-winning task. [The instructions for the bonus-winning task is excluded from this script and it is available upon request.]

When you finish this please raise your hand, [Experiment Assistant] will pick up your bonus winning procedure decision sheets and we will give you a survey.

\section{C.3 Pre-Survey}

INSTRUCTIONS

INDIVIDUAL ID:

\section{(one copy per person)}


Thank you for volunteering to participate in this economics experiment. The instructions you are reading are self-explanatory. We will read these instructions aloud so please follow along. You and the person you are paired with in this experiment will always be reading the exact same documents; there is no deception involved. The instructions have been designed with an emphasis on clarity (which at times leads them to be a little repetitive). The experiment has been designed to use standardized procedures (which at times leads the experiment to feel a little formal). We will not answer any questions during the experiment. If you have any questions, you should read back through the instructions. Now that the experiment has begun, please do not talk unless you are instructed to do so. However, if at any time you wish to end your participation in the experiment, please notify the experimenters immediately.

You have received either orange or green cards with your personal ID Number, and you have an envelope that is either orange or green. Please remember whether you are ORANGE or GREEN in all future portions of this experiment.

ORANGEs and GREENs participate in most of the experiment in ORANGE-GREEN pairs. In this first portion of the experiment, which will take about ten minutes, each ORANGE-GREEN pair will get to know each other. This is the only exception to the experiment's NO-TALKING rule.

You will now spend ten minutes talking with each other and jointly filling out the enclosed ORANGE GREEN QUESTIONNAIRE (front and back) and the accompanying LIST PAGE. When you are finished, please be sure the total numbers of names on the List Page has been written down under Question 8 on the Questionnaire (back), and then have the ORANGE person pocket the List Page, so that researchers never see the names; this protects your anonymity. Put the completed ORANGE-GREEN

QUESTIONNAIRE, into the WHITE ENVELOPE, and drop the envelope in the box indicated by the monitor. (Box will be located at the front of the room) These instructions can then be trashed.

Begin talking for ten minutes when the monitor instructs you to do so. Please do not stop until the monitor instructs you to stop. Even if you do not think you know anyone in common, please keep trying to uncover some connections between the two of you, however remote they may be. It is important to use the entire 10 minutes.

\section{ORANGE -GREEN QUESTIONNAIRE}

\section{GROUP ID:}

(one copy per pair)

Questions: (Try to come to agreement on the answers to these questions. If you absolutely cannot agree on a particular question, feel free to enter two different answers.)

1. Have the two of you ever met before?

If yes, continue with parts $a$ and $b$. 
1a. When did you first meet (month and year, MM/YYYY)?

1b. Approximately how many times have you spoken in the last six months?

2. Do you live in the same house/apartment/dormitory?

2a. If yes: do you share a room?

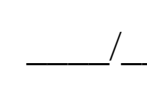

2a. If yes: do you share a room?

3. Are there any extracurricular activities in which you both participate?

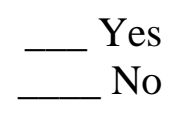

Yes

Yes

No

3. Are the any extracuricular activities in which you both participte?

Yes

No

4a. If yes, enter the number of extracurricular activities in which you both participate:

4. Have the two of you ever spent time together socially (outside of formal extracurricular activities)?

5a. If yes: approximately how many times have you spent time together socially during the last six months?

5. Are the two of you in (or planning to be in) the same concentration?

6. How would you describe your relationship?

Know each other very well.

Know each other pretty well.

Know each other a little.

Recognize each other.

Don't recognize each other.

If the two of you know each other, continue with the lettered questions below; otherwise skip to question 7.

6a. Have you ever had any disagreements? (Pick one answer from the list below.)

No, never.

Only one minor disagreement.

Occasional minor disagreements.

One or two major disagreements.

Many major disagreements.

6b. Would you describe your relationship as a friendship?

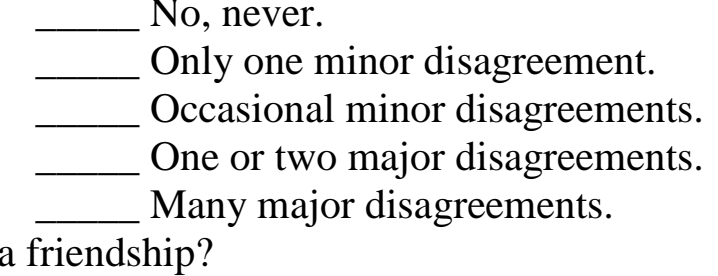

Yes

Would you describe your relationship as a friendship?

6c. If yes: how close is your friendship?

Extremely close friendship.

Very close friendship. 
Close friendship.

Casual friendship.

7. How likely is it that the two of you will see each other - intentionally or unintentionally - at some point in the next two weeks? (This includes accidental meetings, like seeing each other at MSC.)

Very likely.

Somewhat likely.

Somewhat unlikely.

Very unlikely.

8. Please use the List Page that came with this Questionnaire to list all of the people that you know personally and in common (a mutual acquaintance counts, Tiger Woods probably does not). Think about information like your house, concentration, extra-curricular activities, etc.., which will help you make this list as complete as possible). Finally, count all of the people on your list and enter that number here:

Give the List Page to Person ORANGE, who should pocket it. We don't want the list because it might compromise your anonymity vis-a-vis the experimenters. Do not put any names from the List Page here on the Questionnaire.

\section{LIST PAGE}

(one copy per pair)

List of all of the people that you know personally and in common (for example, a mutual acquaintance counts, but Tiger Woods does not).

Remember to think about information like your house, concentration, extracurricular activities, etc.., which will help you make this list as complete as possible.

When you are done, remember to count all of the entries on the list, and enter the number under question 8 on the ORANGE-GREEN QUESTIONNAIRE. Then give this page to Person ORANGE, who should pocket it. We don't want the actual names because they might compromise your anonymity vis-a-vis the experimenters. 


\section{C.4 Transfer Game Decision Sheet (No Promise) DECISION FORM}

GROUP ID

Please write only what you have been asked to write. Extraneous marks, anywhere on this form, invalidate the Transfer Game; in that case neither one of you will be paid for your participation in this portion of the experiment.

This section is to be completed by person ORANGE.

\section{ORANGE's Transfer to GREEN}

I, person ORANGE, choose to send \$__ ("sent") of my \$10 to GREEN (it must be a whole dollar amount) and choose to keep $\$$ ("kept"). I understand that GREEN is under no obligation to pay any of this money back. I also understand that any money that I give to GREEN will be tripled by the experimenter. So GREEN will actually receive three times what I send, or \$ ("tripled" - please do this calculation).

This section is to be completed by person GREEN.

Refer to the above amounts "kept" and "tripled", when you fill out this section.

\section{GREEN's Transfer Back to ORANGE}

I, person GREEN, choose to send \$ ("sent back") back to ORANGE (it must be a whole dollar amount). I understand that I am under no obligation to send any money back to ORANGE. Now fill in the payout table below.

ORANGE gets
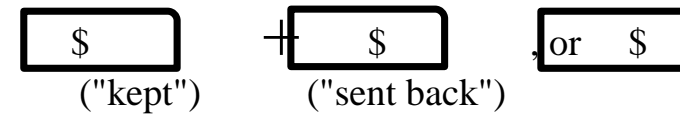

(Orange's winnings); and

GREEN gets
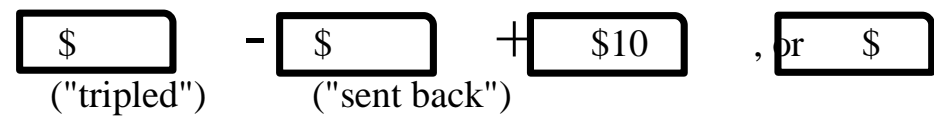

(Green's winnings);

Please leave the section below blank.

FOR USE BY CASHIER ONLY:

Confirmed that ("kept") plus $($ "sent") $=\$ 10 ; 3$ times $($ "sent") $=$ ("tripled"); and ORANGE's and GREEN's winnings above are calculated correctly and disbursed accordingly.

CASHIER: 


\section{C.5 Trust Game Decision Sheet (Promise)}

\section{DECISION FORM}

GROUP ID

Please write only what you have been asked to write. Extraneous marks, anywhere on this form, invalidate the Transfer Game; in that case neither one of you will be paid for your participation in this portion of the experiment.

This section is to be completed by person GREEN.

One of these two statements must be checked and no other type of message is allowed. Please note that this promise is not binding. Check the box in front of the chosen option below.

\section{GREEN's Message to ORANGE}

I, person GREEN, promise to repay ORANGE at least as much as ORANGE sends me. For example, if ORANGE sends me $\$ 4$, which will be tripled by the experimenters to $\$ 12$, then I will repay ORANGE at least $\$ 4$

I, person GREEN, make no promise to ORANGE.

This section is to be completed by person ORANGE.

ORANGE's Transfer to GREEN

I, person ORANGE, choose to send \$__ ("sent") of my \$10 to GREEN (it must be a whole dollar amount) and choose to keep \$ ("kept"). I understand that GREEN is under no obligation to pay any of this money back. I also understand that any money that I give to GREEN will be tripled by the experimenter. So GREEN will actually receive three times what I send, or \$ this calculation).

This section is to be completed by person GREEN.

Refer to the above amounts "kept" and "tripled", when you fill out this section.

GREEN's Transfer Back to ORANGE

I, person GREEN, choose to send \$__ ("sent back") back to ORANGE (it must be a whole dollar amount). I understand that I am under no obligation to send any money back to ORANGE. Now fill in the payout table below.

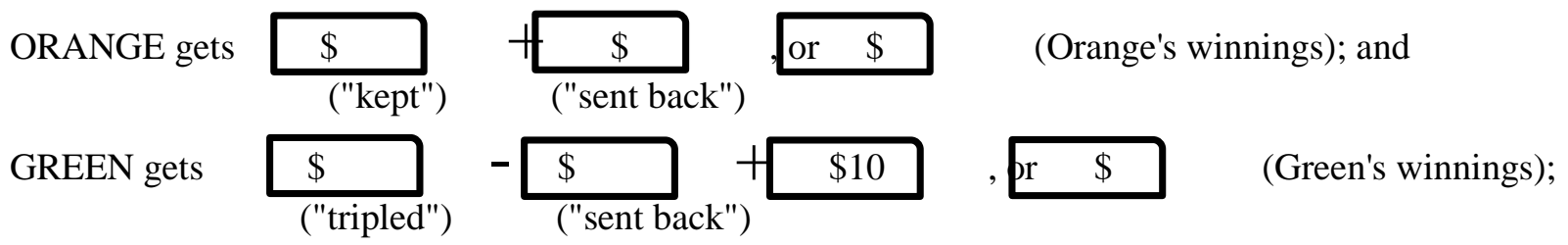

Please leave the section below blank.

FOR USE BY CASHIER ONLY:

Confirmed that __ ("kept") plus __ ("sent") $=\$ 10 ; 3$ times $(" s e n t ")=$ ("tripled"); and ORANGE's and GREEN's winnings above are calculated correctly and disbursed accordingly. CASHIER: 


\section{C.6 Post-Survey}

\section{TRANSFER GAME QUESTIONNAIRE INDIVIDUAL ID}

Please answer the following questions to the best of your ability. For most of the questions provide answers by circling a number on a 1 to 6 scale. Put a checkmark in front of the chosen multiple-choice and yes/no answers. Answer the open-ended questions to explain your opinions and experiences.

1. What do you think this portion of the experiment (The Transfer Game) was about?

2. How well did you understand the structure of the experiment?

$\begin{array}{llllllll}\text { (not at all well) } & 1 & 2 & 3 & 4 & 5 & 6 & \text { (very well) }\end{array}$

Please explain.

3. How clear were the instructions written?

$\begin{array}{lllllllll}\text { (clear) } & 1 & 2 & 3 & 4 & 5 & 6 & \text { (very clear) }\end{array}$

Please explain.

4. How clear were the monitor's instructions?

$\begin{array}{lllllllll}\text { (clear) } & 1 & 2 & 3 & 4 & 5 & 6 & \text { (very clear) }\end{array}$

Please explain.

5. How good do you feel about your choices?

$\begin{array}{lllllllll}\text { (good) } & 1 & 2 & 3 & 4 & 5 & 6 & \text { (very good) }\end{array}$

Please explain.

6. In retrospect what, if anything, do you wish you had done differently? Please explain. 
7. How much did you enjoy participating?

$\begin{array}{llllllll}\text { (not at all) } & 1 & 2 & 3 & 4 & 5 & 6 & \text { (very much) }\end{array}$

Please explain.

8. Is there anything else you would like to tell us? 